\title{
THE ROCKCLIFFE ICE WAGON
}

[Summarized from a note by Flight Lieutenant J. W. Wilkins, R.C.A.F., in the Roundel, Vol. 3, No. 8, 1951, p. 38-42, and information in the Arctic Circular, Vol. 3, No. 2, 1050, p. 22-23, and The Times of 8 and 18 August 1950.]

Since 1939 a number of anti-icing and de-icing experiments have been made with aircraft of the Royal Canadian Air Force. After testing various types of equipment, it was decided that the electro-thermal de-icing system gave the best results. Thus it was found that to prevent ice formation demands excessively heavy electrical installation, and it is preferable to allow ice to form unhindered for a short time, and then to apply sufficient heat to cause a thin film of water to form between the adhering ice and the airscrew blades or wings, thus causing its dislodgement.

In March 1950 a four-engined North Star aircraft, known as the Rockcliffe Ice Wagon, began a series of flights to test the electro-thermal de-icing system more thoroughly. This work has been directed by J. L. Orr, head of the Low Temperature Laboratory of the National Rescarch Council.

The crew of the aircraft at present comprises:

Flight Lieutenant J. J. Higgins, Pilot

Flight Lieutenant T. J. Evans, Co-pilot

Flying Officer IH. A. Smith, Navigator

Flying Ollicer 'T. A. R. Harris, Wireless operator

Scrgeant A. R. Fricday, Flight engincer

Two airframe technicians, three llight mechanics, an clectrician, an assistant wircless operator and an instrument technician make up the crew.

The following scientists of the Low Temperature Laboratory have taken part in the tests:

$$
\begin{array}{ll}
\text { D. Fraser, Leader } & \text { R. C. Brown } \\
\text { E. H. Bowler } & \text { J. A. Lynch }
\end{array}
$$

K. G. Pettit represented the Department of Transport.

A dorsal fin, $8 \mathrm{ft}$. high and $10 \mathrm{ft}$. long, with a "parting strip" 1 inch wide on its leading edge, was fitted into the fuselage. During the tests the strip was continuously heated to prevent ice forming on it. The ice which formed on either side of the hcated strip was allowed to remain for a few minutes before the "shedding" zone was heated, and the ultimate removal of the ice was brought about by aerodynamic forces acting upon it.

Instruments were also carried for measuring the density of clouds and their water content, for determining the effect of ice on the airscrews, and for giving the pilot visual warning of icing conditions.

Electrical power was provided by two $60 \mathrm{kw}$. electrical alternators, driven by the two outboard engines, which supplied an electrical sub-station in the fuselage. From this point current could be distributed through controls on the observers' panels.

In August 1950 the Rockcliffe Ice Wagon, which is normally based at the Experimental and Proving Establishment at Rockcliffe, visited the United Kingdom to demonstrate the electro-thermal method of de-icing. 